UNITED STATES

DEPARTMENT OF THE INTERIOR

GEOLOGICAL SURVEY

Mapping Luminescence of Uranium-Bearing Sandstones

Using an Imaging Fraunhofer Line Discriminator

Robert D. Watson and Arnold F. Theisen

U.S. Geological Survey

Flagstaff, Arizona 86001

1977

Open-file report

77-743 


\section{Contents}

\section{Page}

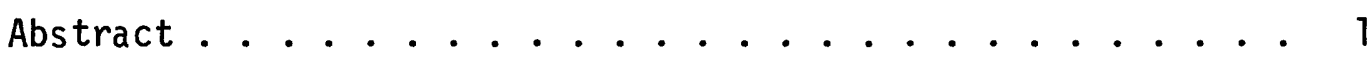

Introduction ................. 2

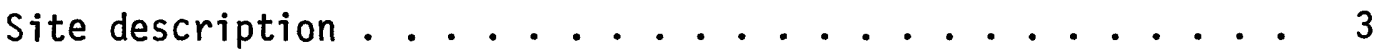

Fraunhofer Line Discriminator imaging system . . . . . . 4

Data acquisition and analysis........... 5

Discussion.................. 7

References................. 10 


\section{Il lustrations}

Page

Figure 1. Location map of survey area .......... . 11

2. Overlay of geologic features. ........ 12

3. Color mosaic photograph of survey area. . . . 13

4. Diagram of imaging system ......... . 14

5. Overlay of reflectance values ........ 15

6. Overlay of luminescence values. . . . . . . 16 


\title{
Mapping luminescence of uranium-bearing sandstones using an imaging Fraunhofer Line Discriminator
}

\section{by}

\author{
Robert D. Watson and Arnold F. Theisen \\ U.S. Geological Survey \\ Flagstaff, Arizona 86001
}

\section{Abstract}

Measurements with a Fraunhofer Line Discriminator (FLD) imaging system over uranium-bearing sandstones in the Galisteo Formation, Sandia Mountains, New Mexico, show that luminescence of these sandstones is detectable and in general agreement with their distribution as mapped on the ground. The FLD imaging system coupled with a color television monitor and recorder, provides an inexpensive and reasonably accurate method of mapping the extent of luminescent materials, without the need of sophisticated aircraft image-motion compensation. 


\section{INTRODUCTION}

Recent laboratory measurements of the luminescence of selected samples of radioactive rocks and minerals (Watson and Theisen, 1977), using a Fraunhofer Line Discriminator (FLD) positioned 1 meter above the samples, indicated that most of the materials studied should be detectable with a FLD operating at aircraft altitudes. One of these materials, uranophane (uranium-bearing) sandstone, is found in the Sandia Mountains and vicinity near ATbuquerque, New Mexico. This material is luminescent at the 589.0 nanometer Fraunhofer wavelength. A field experiment was designed to:

1) Provide an early test of an airborne FLD imaging system. In earlier work (Watson and Hemphill, 1976), the FLD had been limited to operation in a non-imaging mode only; operation in an imaging mode is a recent modification.

2) Correlate values of luminescence obtained from an aerial survey of uranium-bearing sandstones with results obtained from ground based measurements .

3) Determine the relative accuracy of the imaging technique by correlating the luminescence/reflectance image with the ground scene as recorded on color video tape and on aerial photographs.

The aerial survey was conducted using the U.S. Geological Survey Cessna 337 aircraft on May 27th, 1977 between 11:55 am and 12:15 pm MDT. The survey area, shown in figure 1 , includes about 15.3 square kilometers (5.5 square miles) north and east of the ghost town of Coyote and centered at $106^{\circ} 19^{\prime} \mathrm{W}$ long., and $35^{\circ} 23^{\prime} \mathrm{N}$ lat. 
Flight altitude and aircraft speed were 2286 meters (7500) above mean terrain and 45 meters/second (148 feet/second) respectively. Ground resolution at this aircraft altitude is approximately 38.7 meters ( 127 feet). The flight line was from south to north as shown in figure 1 .

\section{Site Description}

Most of the survey area shown in figure 1 is located north of the area mapped by Kelley (1975) but the general description of the geology of the Sandia Mountains and vicinity has been treated in some detail by Kelley and Northrop (1975). The various igneous and sedimentary rocks exposed in the survey area are of Tertiary and Quaternary age. The uranium-bearing sandstones of Tertiary age are located in the Galisteo Formation, which is overlain by the Espinaso Volcanics as used by Kelley and Northrop (1975). The largest outcrop area of the Galisteo Formation is in a broad, north-striking belt with most outcrops located in the drainage areas of Coyote and Tonque Arroyos (Kelley and Northrop, 1975).

A luminescent yellowish grey gypsiferous shale, included in the Galisteo Formation raised the background luminescence in the FLD image by about 50 counts (a count is a measure of luminescence intensity as derived from raw data from the digital output of the FLD). The flight traversed a region of Quaternary gravels and exposures of the Galisteo Formation. 
Figure 2 is a film overlay of the general surface geology as modified from an unpublished map. A composite color aerial photograph of the area is shown in figure 3.

Fraunhofer Line Discriminator imaging system

The FLD imager (fig. 4) is based on a simple opto-mechanical arrangement which uses a pair of front surface mirrors, one of which is fixed at $45^{\circ}$ with respect to the FLD earth telescope and the other is oscillated to \pm 9.25 degrees with respect.to a parallel position with the $45^{\circ}$ mirror. The linearity and total angle of oscillation is controlled by a precision cam, based on an Archimedes spiral design. The rate of oscillation is determined by an electronically controlled precision DC motor with techometer feedback. The feedback signal is monitored for accurate speed control of one complete sweep (370) per second. A timing disk is mounted on the motor shaft to provide a beginning of sweep trigger, generated by an electro-optical coupler. Ground resolution is determined by the instantaneous one-degree field of view of the FLD. Maximum ground coverage (without overlap) is obtained when the aircraft speed (in meters/second) matches the ground resolution (in meters) of the FLD. For example, with the present system an aircraft speed of 45 meters/second (148 feet/second) and altitude above terrain of 2382 meters (7815 feet) is required for ground area coverage of 80 percent (without overlaps) at a ground resolution of 45 meters (148 feet). 
The width on the ground for this example is 1620 meters. The imaging system as currently designed has no mechanical correction for aircraft yaw, pitch, and roll; however, the scene as viewed by the scanner is also recorded on color video tape, which makes it possible to correct the distortions in the scene. In order to geometrically rectify the scene, sweep position and orientation, and center line position are obtained from the television scene and this information is used to correct the scanner image. This procedure permits only first order correction because center line and sweep position are interpretable only to within \pm one resolution element. However, by judicious choice of flying conditions, this effect can be minimized.

Data Acquisition and Analysis

The heart of the data acquisition system is a Motorola $a^{1 /}$ M6800 microprocessor, with 10,000 words of memory. The system uses a 1 megahertz clock and has an interface board specifically designed for use with the FLD. The M6800 is programmed to organize FLD data in blocks of 15 sweeps with 36 resolution elements per sweep. The FLD provides data at 40 Hertz (40 resolution elements/second) plus a data valid pulse.

\footnotetext{
I/

Use of trade names in this paper is for description purposes only and does not constitute an endorsement of the product by the U.S. Geological Survey.
} 
The beginning of sweep trigger, the data valid pulse, and FLD imaging system data are fed into the computer, where the beginning of sweep pulse produces both a beginning of block and sweep mark, updates block and sweep counters, and sets the computer to accept FLD data valid pulse and data. Both block and sweep counts and beginning of sweep mark are transferred to video monitor and recorder. These three items plus the beginning of block mark (produced every 15 sweeps) are also recorded on digital cassette tape. The data valid pulse causes the computer to transfer to digital tape both the luminescence and reflectance values for each resolution element up to 36 resolution elements per sweep. The remainder of the time in which the 4 resolution elements would have been acquired is used for scanner mirror return to beginning scan position. FLD data, recorded on digital tape, are transferred to computer memory, where either luminescence or reflectance data for each resolution element can be analyzed and assigned a character representing either a specific value or a range in values. These characters are then reproduced by a printer with a capability of producing 94 distinct characters plus a blank. Grey scale slicing with a preselected window for luminescence or reflectance is possible. The reflectance values shown in figure 5 were scaled for seven levels, the first three with an 8 percent window, and the last four with 2 percent windows. The corresponding luminescence shown in figure 6 were scaled for six levels of 50 count differences (on a scale of 0000 to 9999 counts). The printer was programmed to produce data in a format representing the total unrectified scene. 
That part of the image of interest is then appropriately scaled $(1: 12,000$ for the May 27th image) using a PDP-11 computer and printed out in standard 14 inch, 132 character format, with appropriate block and sweep numbers. The scanner scene was then geometrically rectified for each sweep to produce the luminescence and reflectance overlays (figs. 5 and 6 ).

\section{Discussion}

Figures 5 and 6 when overlain on figure 3 , show the reflectance and luminescence profiles relative to the ground. Reflectance covers the full range of values observed, from 0.0 to 32 percent, while 1 uminescence represents values ranging from 200 to 600 counts as compared to a general background of less than 100 counts. Figure 2 is an overlay of the general surface geology. The following observations are noted from these overlays:

1) There is a belt of luminescence highs (250 to 400 counts) on the west side of the drill site pattern located at the south end of the flight area (fig. 3). These highs do not correlate with reflectance highs and possibly represent material where reflectance has somewhat decreased through weathering.

2) Most of the high values in luminescence are in either the Galisteo Formation or the "Espinaso Volcanics," where the volcanics have been cut by man or natural processes.

3) The alluvium and gravels are relatively free from luminescence highs except in drill sites. 
4) Immediately to the west of the Espinaso volcanics, north of Tongue Arroyo, is a broad belt of grey and grey buff to yellowish buff sandstone with a 24 to 32 percent reflectance. The luminescence of this sandstone varies between 200 to 350 counts, with most values between 200 and 250 counts. In the north and south extensions of this belt, adjacent to the gravels, luminescence highs vary between 250 and 350 counts.

5) Within the Galisteo Formation, between red beds, a belt of exposed grey sandstone with a reflectance ranging from 16 to 24 percent, shows moderately high luminescence with most values between 200 and 250 counts. At the south end of this belt and extending slightly to the west is a region with 7 uminescence values between 200 and 300 counts. At the north end of this belt and again extending slightly west is another region of luminescence values between 200 and 300 counts.

6) Farther west of the red beds are scattered luminescence values varying between 200 and 250 counts with a general north-south trend. Two isolated highs occur on the extreme north and south end of the flight area within the Galisteo Formation that have luminescence values of 550 600 counts (south) and 400-450 counts (north).

From these observations, it is concluded that the highest values of 1 uminescence occurs in the Gal isteo Formation, which contains the uranophane sandstones. Luminescence in this formation ranges from 2.0 to 6.0 ppb rhodamine wt equivalent ( 100 counts equals 1 ppb, Watson and Hemphill, 1976), an order of magnitude less than measured with the FLD in ground configuration (Watson and Theisen, 1977). This difference is not surprising due to the larger resolution element viewed by the FLD at approximately 2200 meters above terrain and the non-homogeneity of materials within the field of view. 
The quality of the interpretation of the image is limited only by the accuracy of the location of the flight center line and sweep at the precise moment when the block and sweep are identified. Although all sweeps are approximately by straight lines in the scene, little error is introduced by this method. Good correlation of FLD reflectance and luminescence with surface features, observed on the TV monitor and in figure 3 , such as the definition of boundaries of gravels and volcanic capped ridge is evidence of this fact. 


\section{References}

Kelley, V. C., 1975, Geologic map of Sandia Mountains area, New Mexico: New Mexico Bur. of Mines and Mineral Resources Mem., 29, map 1. Kelley, V. C., and Northrop, S. A., 1975, Geology of Sandia Mountains and vicinity, New Mexico: New Mexico Bur. of Mines and Mineral Resources, Mem., 29, 136 p.

Watson, R. D., and Hemphi11, W. R., 1976, Use of an airborne Fraunhofer Line Discriminator for the detection of solar stimulated luminescence: U.S. Geol. Survey open-file rept. 76-202, 110 p., 29 illus. Watson, R. D., and Theisen, A. F., 1977, Luminescence properties of selected radioactive rocks and minerals: U.S. Geol. Survey open-file rept. $77-293,10 \mathrm{p}$. 
Figure 1. Location map of the flight area (outlined) over Tongue and Tuerto Arroyos adopted from the U.S.G.S. Hagan and San Felipe Pueblo NE, New Mexico quadrangle maps. Dashed line represents center of flight path. Centered at $106^{\circ} 19^{\prime} \mathrm{W}$ long. $35^{\circ} 23^{\prime} \mathrm{N}$ lat. 
Figure 2. Geologic Map overlay of the area shown in figure 1. 
EXPLANATION

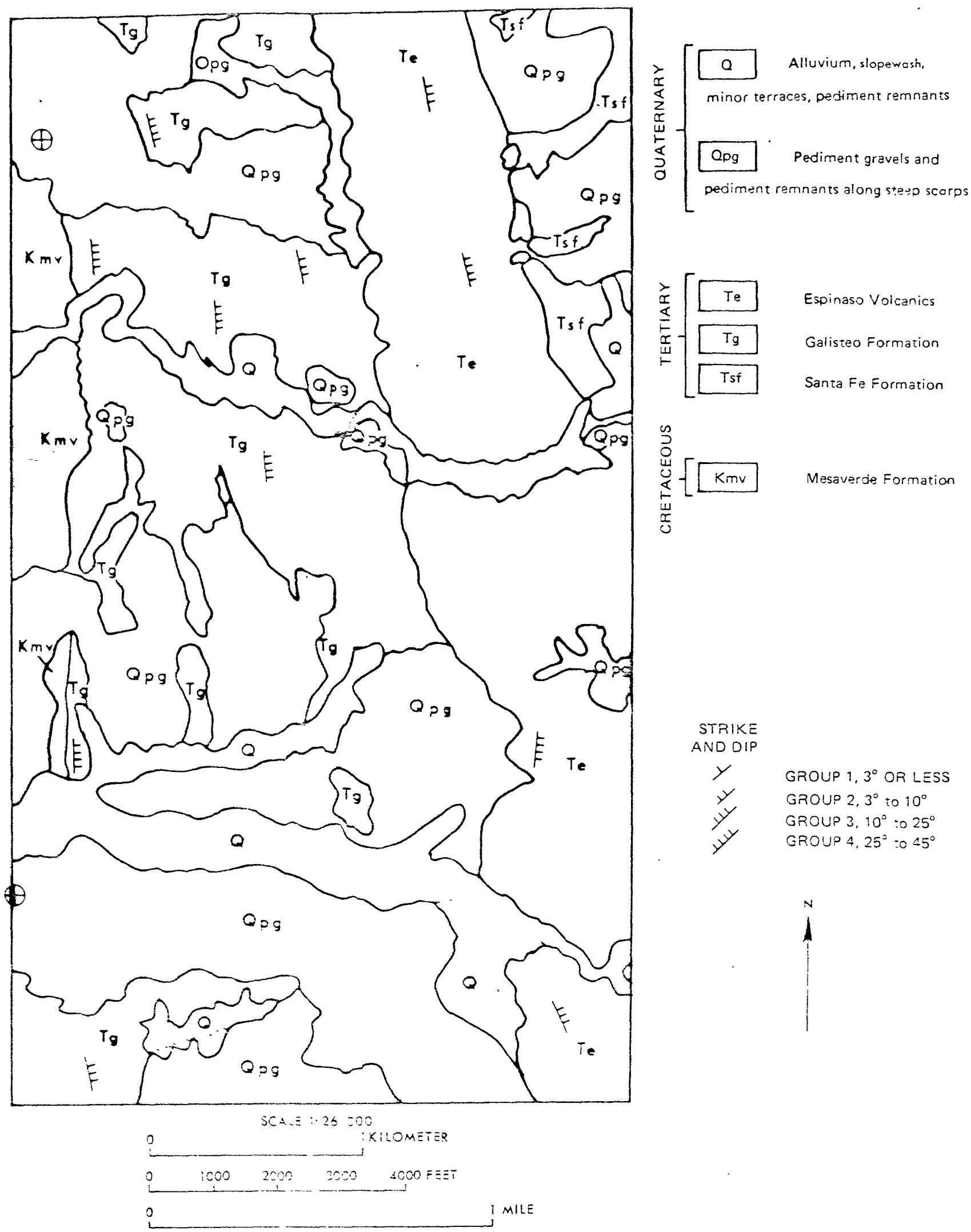

figares 2 paste. 
Figure 3. Color mosaic photograph at $1: 26,000$ scale of the area shown in figure 1. Registration marks permit alignment of overlays 2,5 and 6. 


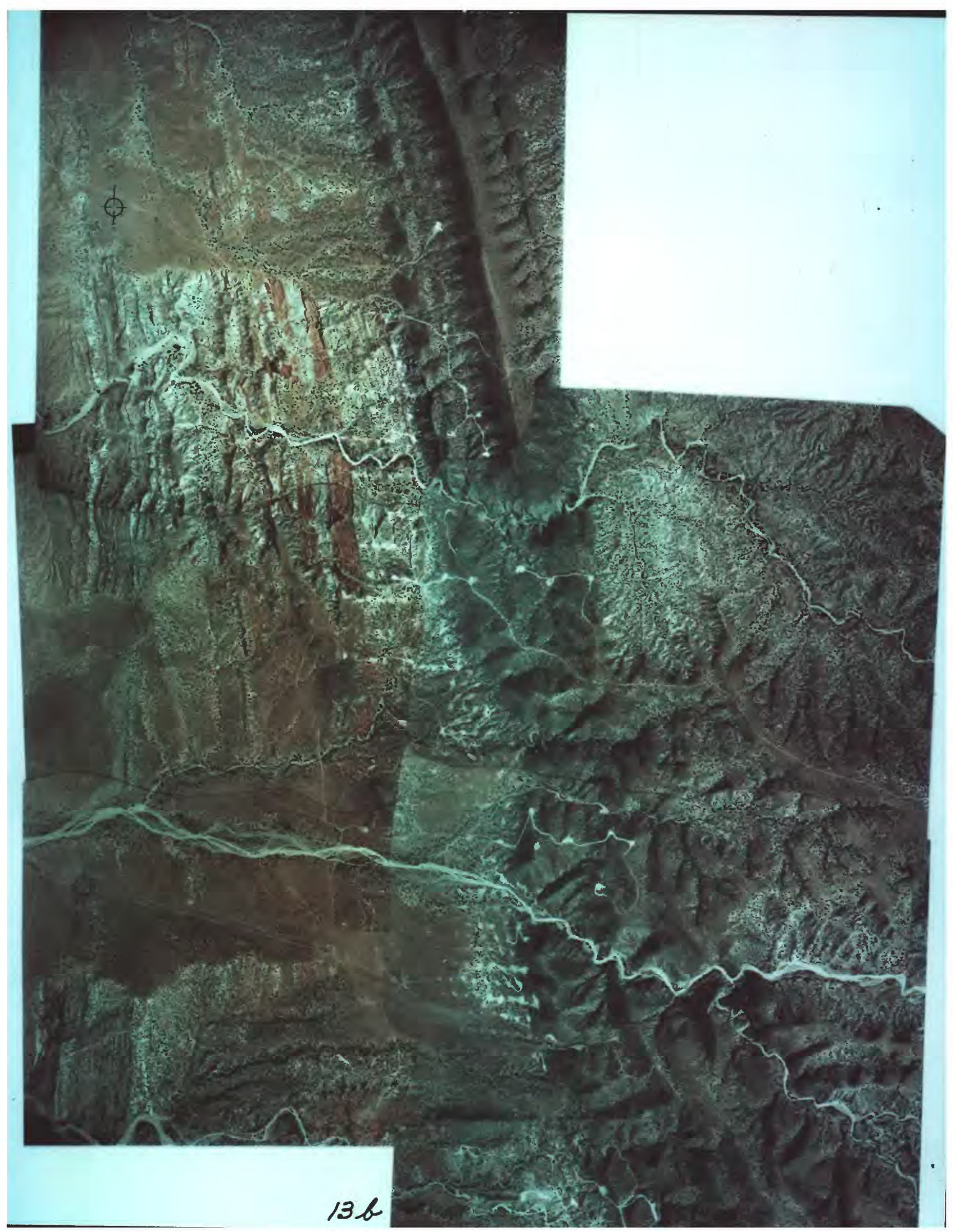




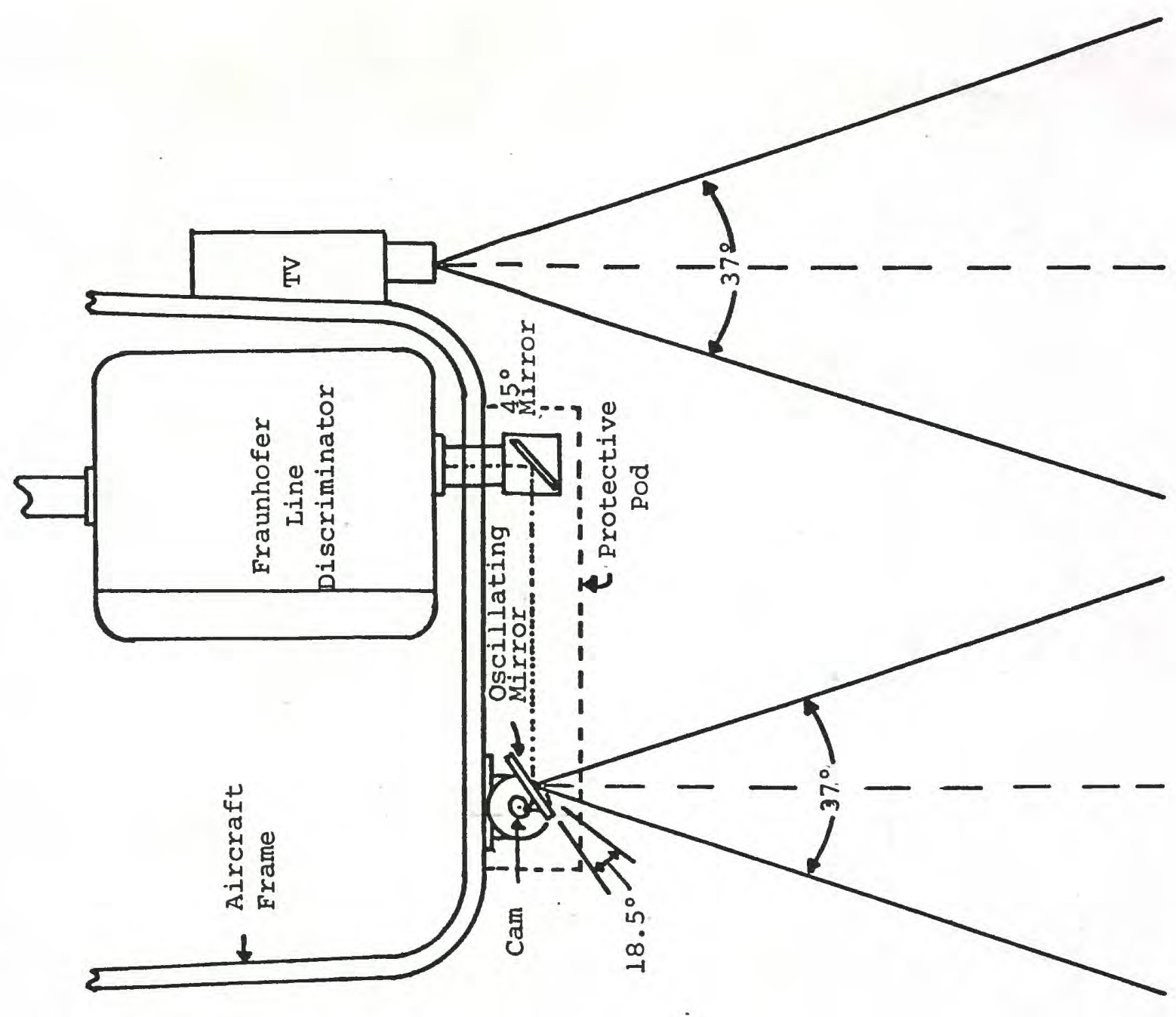

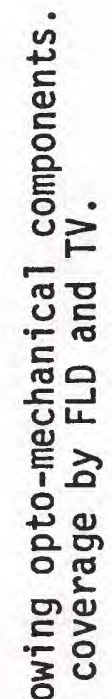

동믈

틍오

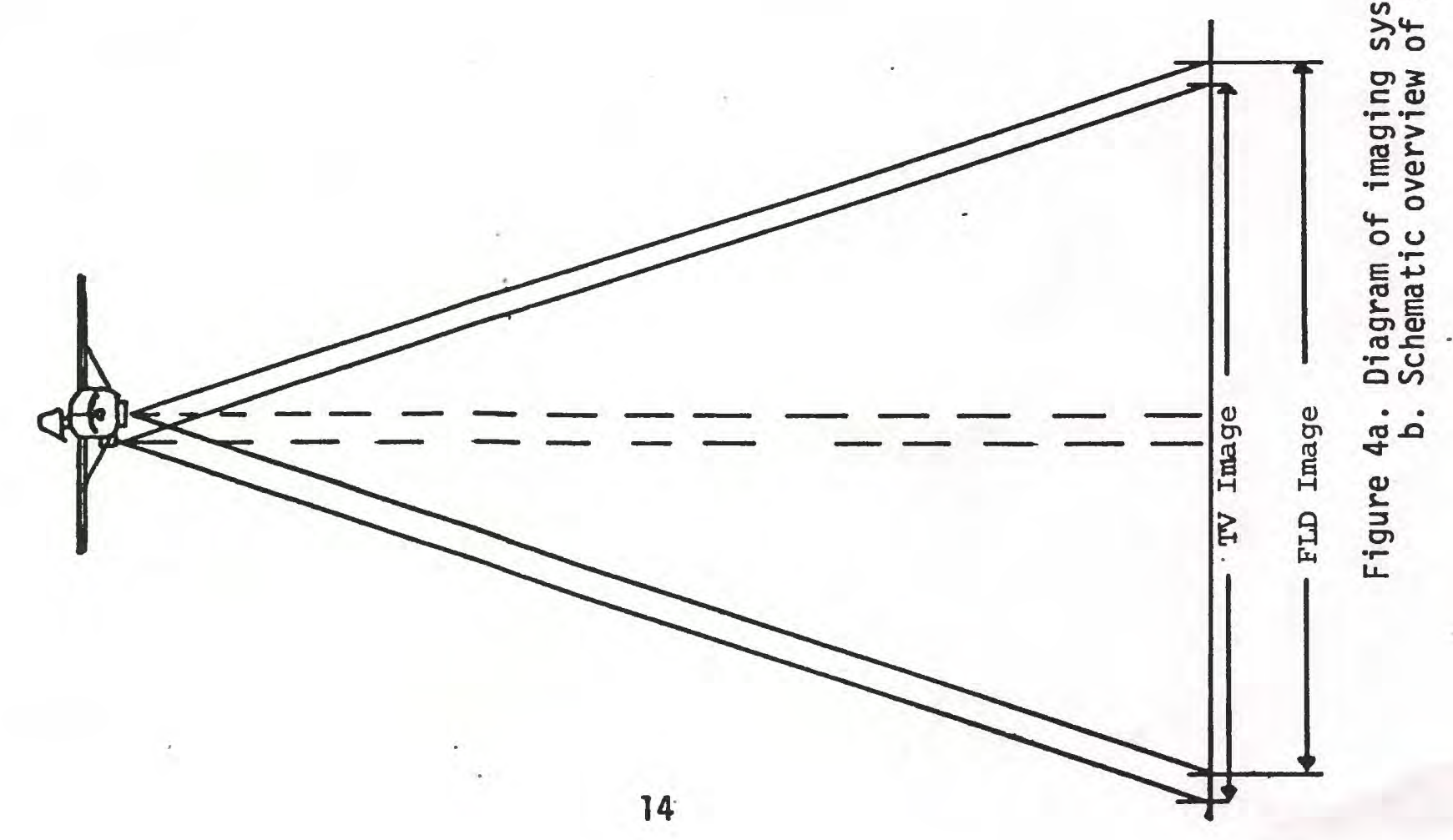




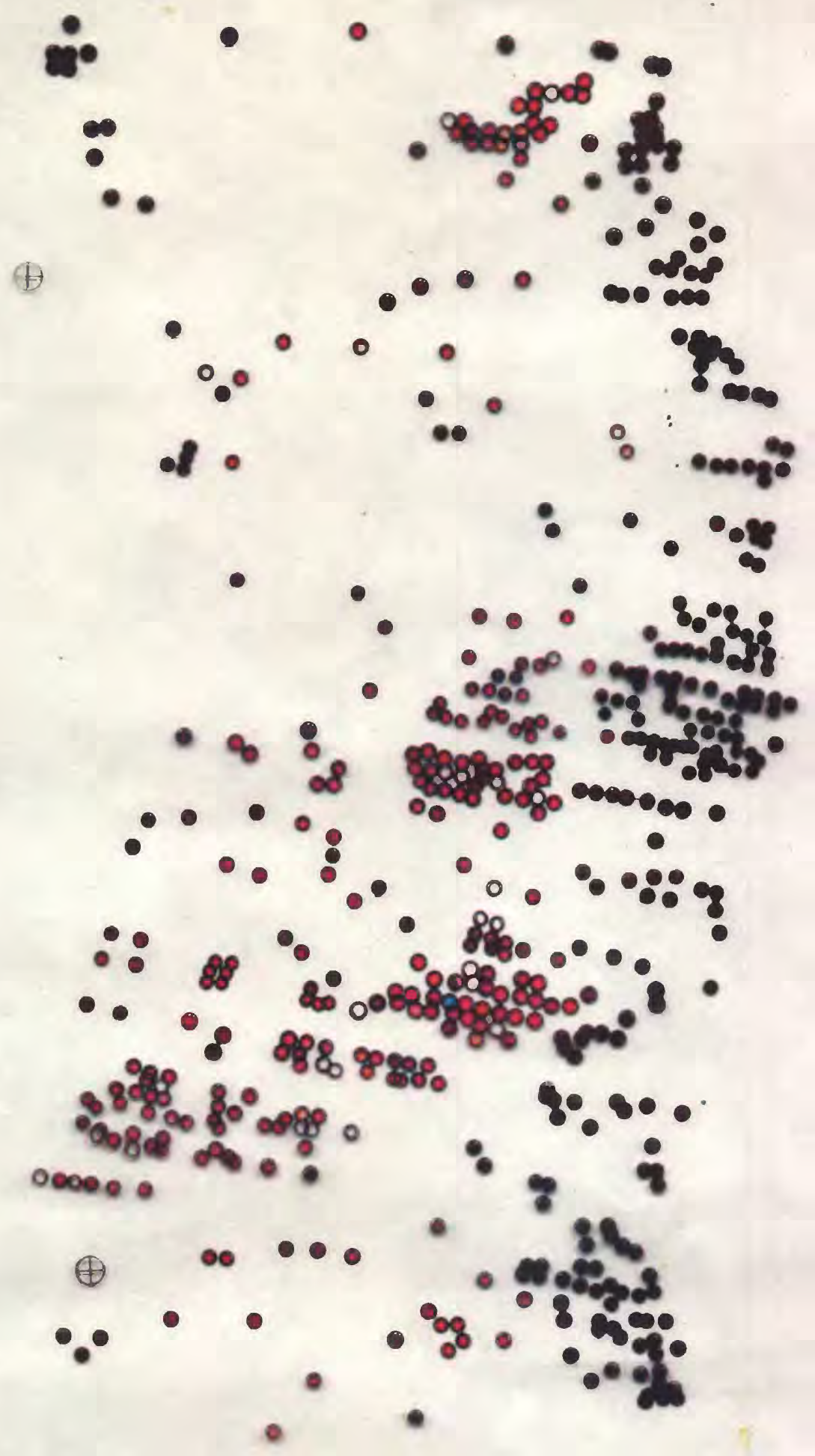

Figure 5. Overlay of the reflectance values obtained with the FLD imaging system and coded as follows: $0.0-8.0$ percent (black), 8.0-16 percent (blue), 16-24 percent (blank), 24-26 percent (purple), 26-28 percent (pink), 28-30 percent (clear) and 30-32 percent (brown). 


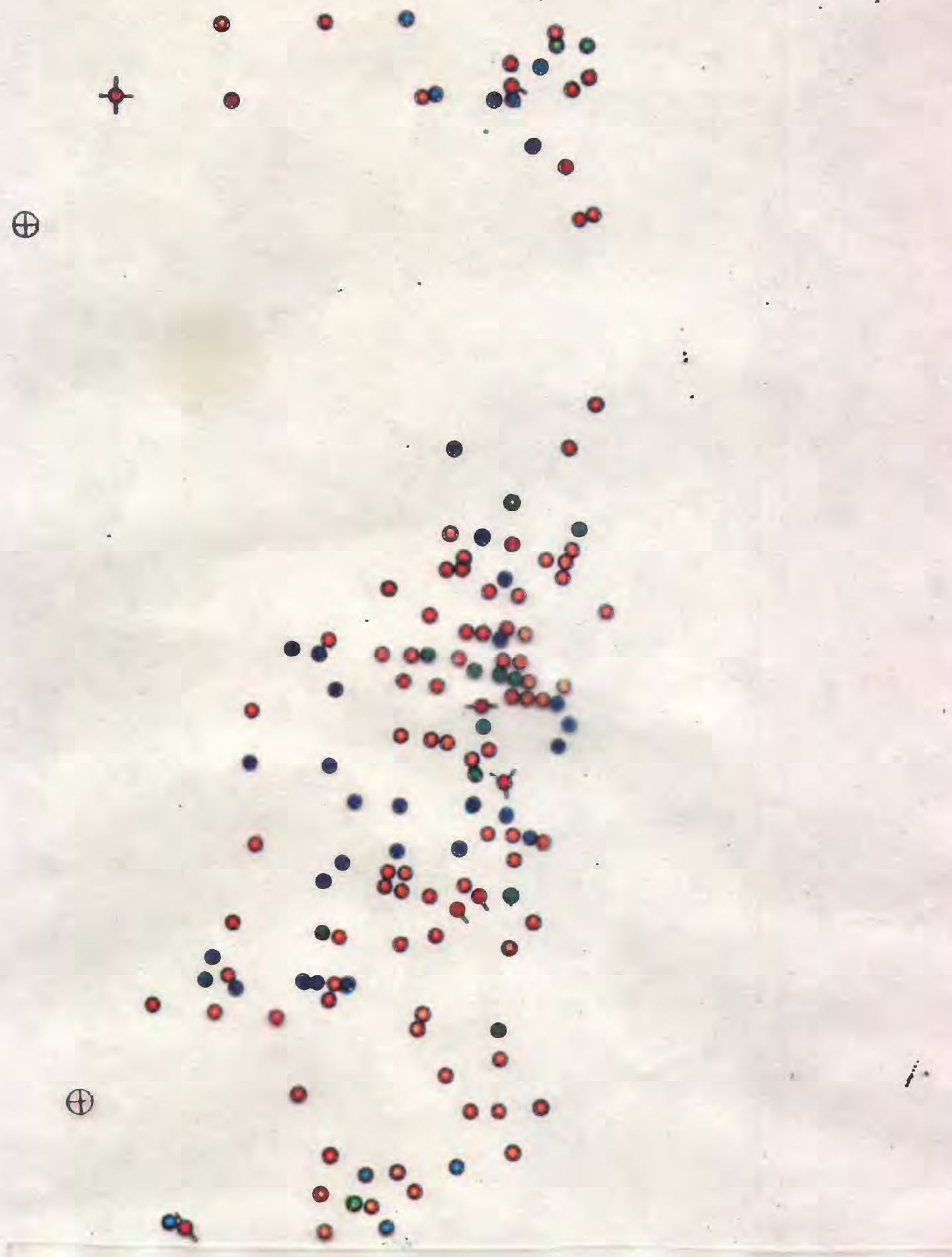

Figure 6. Overlay of the luminescence values obtained with the FLD imaging system and coded as follows: 200-250 (brown), 250300 (blue), 300-350 (green), 350-400 (orange/single tick), 400-450 (red/two ticks), 450-500 (red/three ticks), 500-550 none, 550-600 (red/four ticks). 